\title{
Corrosion Evaluation of SS-304 Stainless Steel for the Application to Heat Pumps
}

\author{
C. Cuevas Arteaga*, J. Uruchurtu Chavarín, Miguel A. Martínez G. \\ Universidad Autónoma del Estado de Morelos, Centro de Investigación en Ingeniería y \\ Ciencias Aplicadas, Av. Universidad 1001, col. Chamilpa, C.P. 62210, Cuernavaca, Morelos, \\ México
}

Received 9 February 2004; accepted in revised form 6 January 2005

\begin{abstract}
Studies of the corrosion evaluation of SS-304 stainless steel exposed in aqueous lithium bromide solution have been carried out applying the electrochemical noise technique, polarization curves and the weight loss method. The test temperatures were 50, 60 and $70{ }^{\circ} \mathrm{C}$, and the exposure time was for fifteen days. The main objective was to determine the corrosion rates and the type of corrosion that SS-304 suffers under the mentioned conditions with the purpose of evaluating its application to heat pumps/transformers.

The results showed that at the three test temperatures the type of corrosion was a mixed and pitting process. At $60{ }^{\circ} \mathrm{C}$, it was observed some anodic peaks at the fifth day of exposure, indicating pitting nucleation. From 7 to 12 days a regular and continue pitting process was observed, and then the corrosion process became in generalized type. At 70 ${ }^{\circ} \mathrm{C}$, some isolated and medium intensity peaks were observed, presenting behaviour of some mixed and pitting corrosion. The resistance noise was calculated through a statistical analysis, and then the Stern-Geary equation and Faraday Law were applied to determine the mass loss, which was compared to that obtained from weight loss method. Tafel slopes were determined from experimental polarization curves. To support the metallic oxidation carried out on the stainless steel surface, atomic absorption analysis was made to the solution corrosion products.
\end{abstract}

Keywords: current time series, electrochemical noise, resistance noise, pitting.

\section{Introduction}

Absorption heat pumps/transformers are the only heat exchanger-recovery systems capable of increasing the waste heat temperature to make it useful in an environmental friendly way. Its main use is in operations where latent heat is

\footnotetext{
*Corresponding author. E-mail address: ccuevas@uaem.mx
} 
discharged, especially in drying, evaporation and distillation unitary processes and in heat recovery of cooling plants.

These systems consist basically of a generator, condenser, evaporator, absorber and a heat exchanger. They use a mixture solution of two chemical substances called working fluid and absorbent, the latter with the function to transport the working fluid from the absorption zone to the generation zone where vapor is separated from the absorbent, for further processing and heat recovery.

The common mixture solution used is a $\mathrm{LiBr}$ (absorbent)/water (working fluid) solution, which under system working operating temperature conditions, has been reported as highly corrosive for stainless steel materials making it necessary to use corrosion inhibitors.

The aim of the present work is to evaluate the corrosion resistance of SS-304 stainless steel in $\mathrm{LiBr}$ water solution for its application in absorption heat pump/transformers. To carry out this research, two electrochemical techniques, noise and polarization curves, and the weight loss method were applied.

\section{Experimental procedure}

The corrosive solution was prepared with lithium bromide analytical grade reagents and distilled water. Before preparing the aqueous solution, the solid $\mathrm{LiBr}$ was dehydrated in an electrical stove. $100 \mathrm{~mL}$ of corrosive solution were introduced in a flask, which was collocated on an electrical stove, where the test temperature was reached. The identical electrodes were made of a sheet of stainless steel, which was of commercial specification with composition (wt \%): $18 \mathrm{Cr}-8 \mathrm{Ni}$-BalFe. Each sample was cut to size $2 \mathrm{~mm} \times 3 \mathrm{~mm} \times 5 \mathrm{~mm}$ and ground to 600 grit silicon carbide paper on all faces, rinsed with distilled water, degreased with acetone and dried under a warm air stream. For electrical connection, the specimens were spot welded to an $80 \mathrm{Cr}-20 \mathrm{Ni}$ wire, $150 \mathrm{~mm}$ long and $1.0 \mathrm{~mm}$ in diameter. Glass tubes were used for isolating the $80 \mathrm{Cr}-20 \mathrm{Ni}$ wire from the corrosive solution, and then the specimens were mounted in cross section and embedded in a polyester resin. The size and preparation of specimens, as well as the preparation of corrosion solution were the same for 
potentiodynamic polarization tests and electrochemical noise measurements. The procedure for weight loss method was made according to ASTM Standard G1 and G31 [1, 2], using specimens (in duplicate) of size $10 \times 5 \times 2 \mathrm{~mm}$. The amount of corrosion solution in each experiment was the same for the three techniques.

After weight loss tests, the specimens were cleaned and weighted in an analytical balance. In order to determine the quantity of iron, chromium and nickel that were dissolved during the corrosion process, the corrosion products were analysed by atomic absorption.

Electrochemical methods, namely polarization curves (PC) and electrochemical noise measurements (ENM) were performed. For PC test, the measurements were recorded using ACM Gill 8AC software and instrumentation controlled by a personal computer. PC tests were performed from $-150 \mathrm{mV} / \mathrm{s}$ below to $600 \mathrm{mV}$ above the corrosion potential at a sweep rate of $60 \mathrm{mV} /$ minute. ENM measurements were obtained at 1 reading/second to produce consecutive records of 1024 at $50{ }^{\circ} \mathrm{C}$ and 2048 points at 60 and $70{ }^{\circ} \mathrm{C}$. Data processing included trend removal of the signal by minimum square linear fitting. On each experiment, simultaneous measurements of potential and current noise were made. Potential and current noise data were recorded with a sampling frequency of $1 \mathrm{~Hz}$; measurements were obtained each four hours during 15 days of experimental immersion. Electrochemical noise measurements were performed using an ACM Instrument ZRA (zero-resistance ammeter) coupled to a personal computer which was used to store the data for further analysis.

\section{Results}

\section{Electrochemical noise}

Fig. 1 presents the typical current time series obtained along the test, for two periods of measurement. Low amplitude high frequency random oscillations were observed with average currents of 0.27 and $0.33 \mathrm{~mA} / \mathrm{cm}^{2}$. Also it is seen that all current values are negative, showing the preferential dissolution of one of the working electrodes of the electrochemical cell. These cases presented high frequency and low intensity random oscillations, where there are no localized 
signal events [3]. Fig. 2 presents a current time series obtained after 18 days immersion.

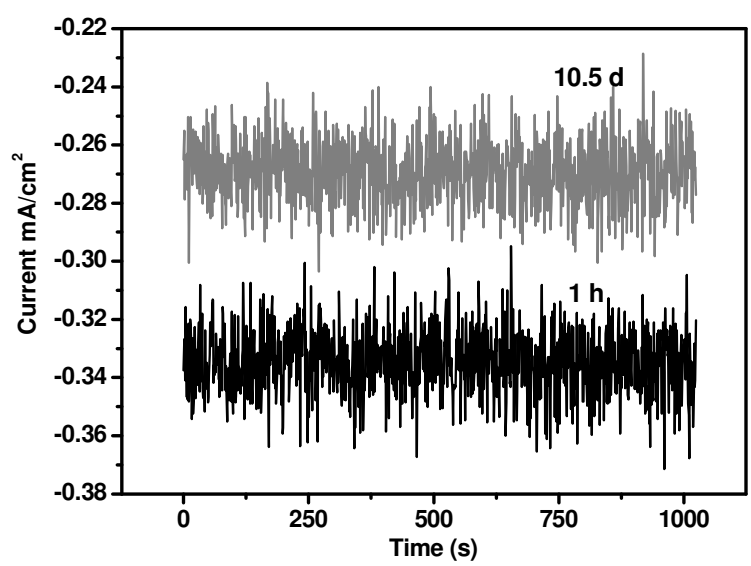

Figure 1. Current time series of SS-304 stainless steel exposed to $50 \mathrm{wt} \% \mathrm{LiBr}-\mathrm{H}_{2} \mathrm{O}$ solution at $50{ }^{\circ} \mathrm{C}$.

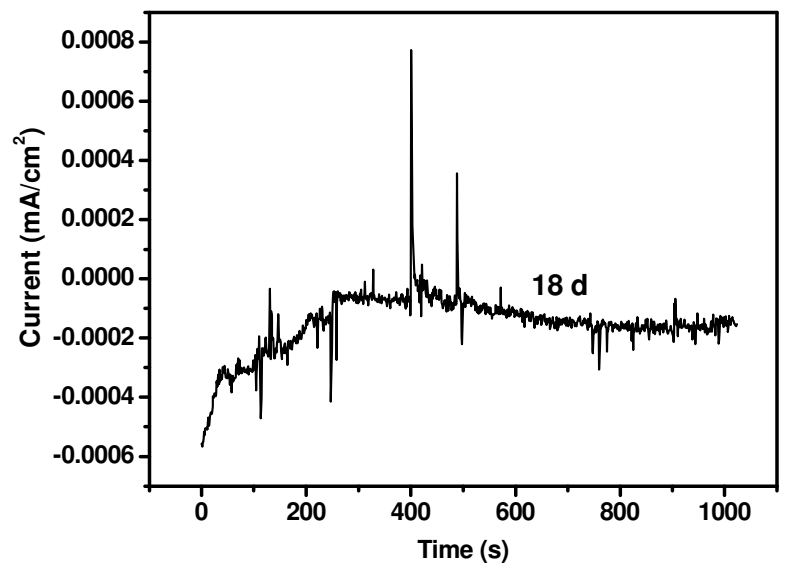

Figure 2. Current time series of SS-304 stainless steel exposed to $50 \mathrm{wt} . \% \mathrm{LiBr}-\mathrm{H}_{2} \mathrm{O}$ solution at $50{ }^{\circ} \mathrm{C}$ showing localized corrosion.

Some transients were observed in both directions superimposed to the random oscillations observed and presented before. These transients are associated to localized events over the metal surface. Fig. 3 presents the potential time series for the three different immersion times described before in current time series. It is easily noticeable the difference between the transient behaviour observed at 
around $170 \mathrm{mV}$ of the corrosion potential and around $80 \mathrm{mV}$, where the noise potential did not show transient behaviour, which is expected.

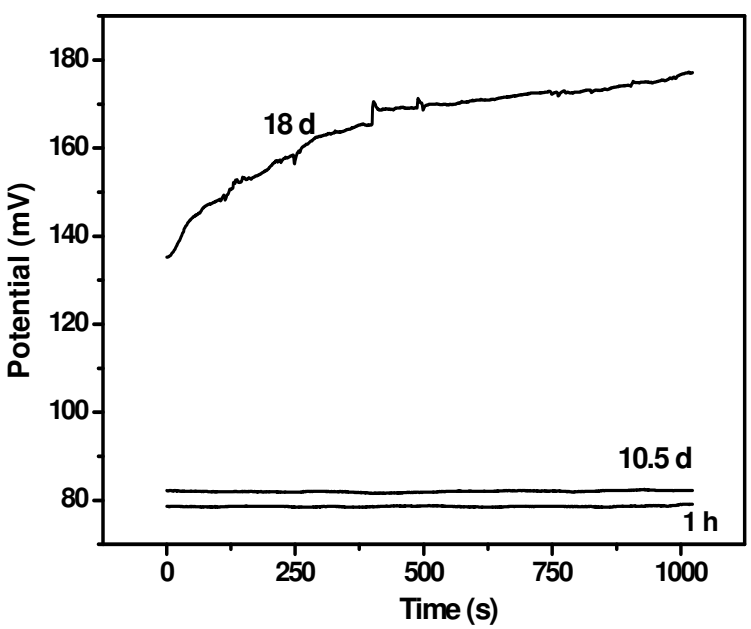

Figure 3. Potential time series of SS-304 stainless steel exposed to 50 wt. $\%$ LiBr- $\mathrm{H}_{2} \mathrm{O}$ solution at $50{ }^{\circ} \mathrm{C}$.

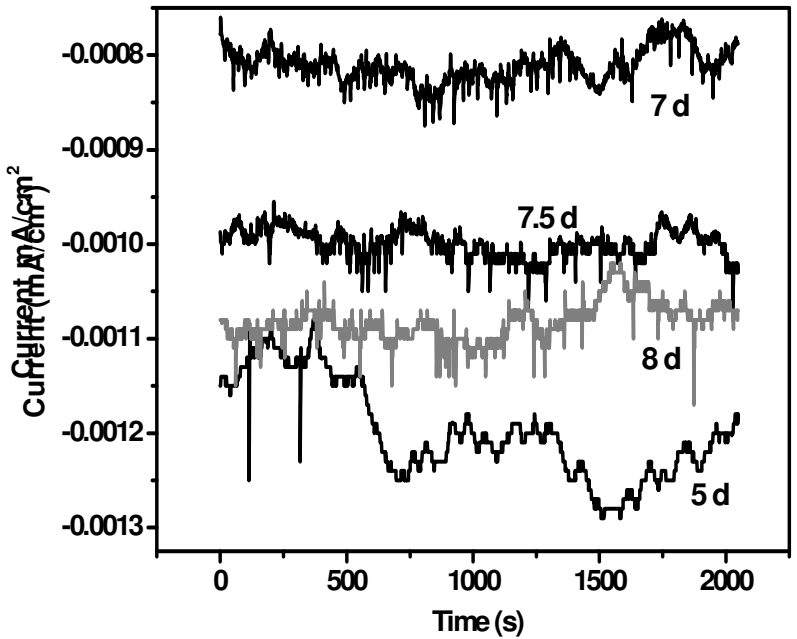

Figure 4. Current time series of SS-304 stainless steel exposed to $50 \mathrm{wt} . \% \mathrm{LiBr}^{-\mathrm{H}_{2} \mathrm{O}}$ solution at $60^{\circ} \mathrm{C}$.

Fig. 4 presents four current noise time series obtained during the experiments ran at $60{ }^{\circ} \mathrm{C}$, where it is noticeable similar structure for all the time series presented. These electrochemical noise signals show that the experimental conditions are 
favourable for pitting nucleation [4]. Slight differences due exist, especially at 5 days where a more undulating behaviour was registered as compared to the others. Therefore a higher standard deviation is expected in these somewhat stochastic behaviour obtained for all the series presented at the 5 day. In this case, it is also observed that the current values are negative, indicating the preferential dissolution of one of the working electrodes. Accordingly, potential noise time series corresponding to the previous current noise time series show the feature characteristics observed (Fig. 5).

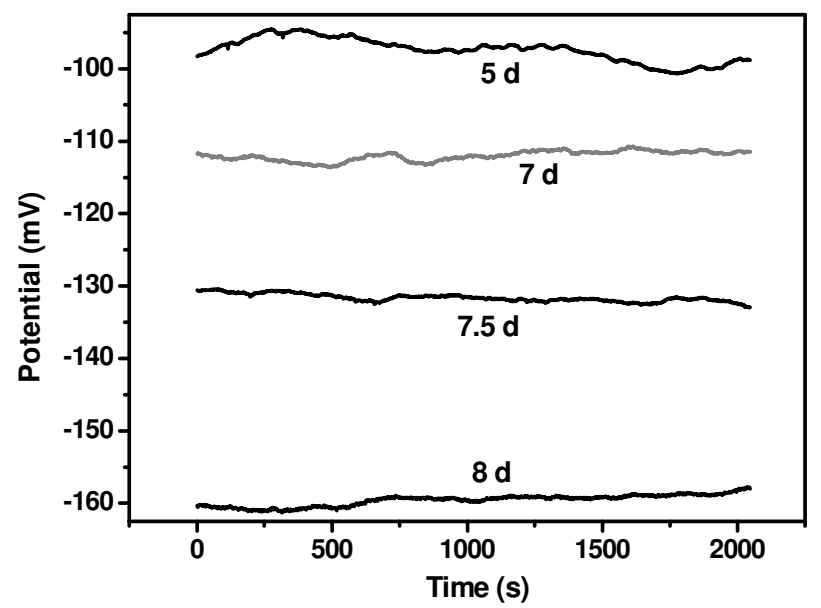

Figure 5. Potential time series of SS-304 stainless steel exposed to $50 \mathrm{wt} . \% \mathrm{LiBr}-\mathrm{H}_{2} \mathrm{O}$ solution at $60^{\circ} \mathrm{C}$.

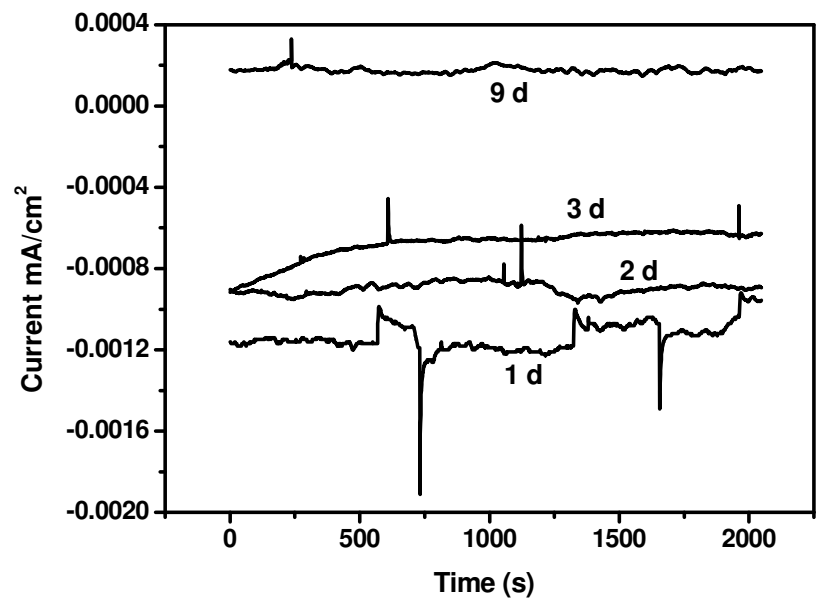

Figure 6. Current time series of SS-304 stainless steel exposed to $50 \mathrm{wt} \% \mathrm{LiBr}-\mathrm{H}_{2} \mathrm{O}$ solution at $70{ }^{\circ} \mathrm{C}$. 
Fig. 6 and 7 show current and potential time series at different days of immersion at $70{ }^{\circ} \mathrm{C}$. Each current time series presents some isolated and high intensity anodic and cathodic picks along the time of the series, indicating some localized corrosion. These transients are typical of a suddenly increase of current followed by an exponential decrease, such as it has been explained by Cottis and Turgoose [5] as a local event. In general, the noise level is very low except in those regions of pitting, presenting a type of mixed corrosion. Mixed corrosion characterizes for a combination of random low amplitude/high frequency signals and high amplitude current transients, such as these time series records are showing [6,7]. Also at the first three days the current values are negative, whereas at the $9^{\text {th }}$ day they are positive, Breslin et al. [8] and Goeller et al. [9]. Alternatively, another explanation depends on the relation between rates of breakdown or repassivation events: fast transient (rupture) and slow exponential recovery (film growth), such as Cheng [10] has reported. It can be said that the current time series showed the nucleation of some pits but not propagation of that pits. The potential time series exhibits low amplitude and low frequency oscillations at 2 and 3 days, meanwhile at 1 and 9 days of immersion some medium amplitude transients are evident, which it might be correlated to localized events, such as it has been showed in current time series.

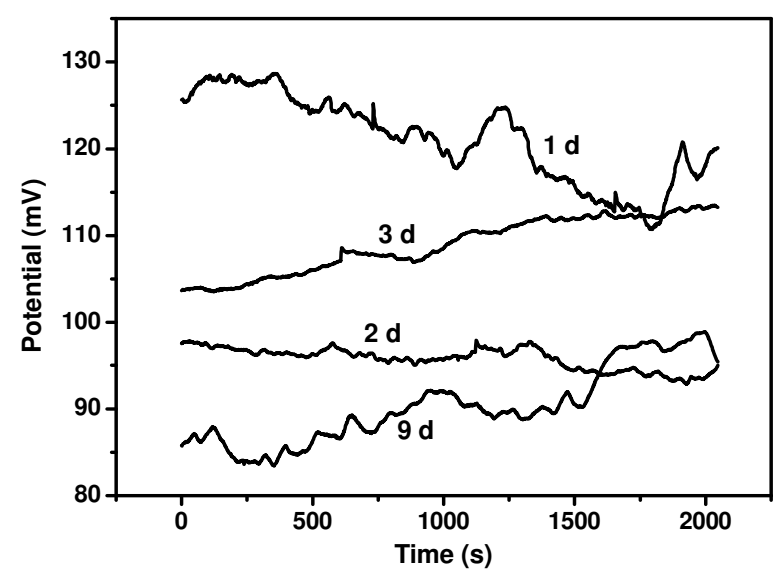

Figure 7. Potential time series of SS-304 stainless steel exposed to $50 \mathrm{wt} . \% \mathrm{LiBr}^{-\mathrm{H}_{2} \mathrm{O}}$ solution at $50{ }^{\circ} \mathrm{C}$. 


\section{Polarization curves}

Fig. 8 presents potentiodynamic polarization curves for the three temperature conditions. At $50{ }^{\circ} \mathrm{C}$ the corrosion potential is $-560 \mathrm{mV}$, showing the anodic region with an almost constant current around $0.03 \mathrm{~A} / \mathrm{cm}^{2}$, related to the corrosion products formed. At $60{ }^{\circ} \mathrm{C}$ the corrosion potential rose to about -370 $\mathrm{mV}$ turning the anodic region into a current limit region around $1.1 \mathrm{E}-3 \mathrm{~A} / \mathrm{cm}^{2}$. Finally, at $70{ }^{\circ} \mathrm{C}$ the corrosion potential increased again to $-300 \mathrm{mV}$. These changes in the anodic direction appear to be indicative with the formation of corrosion products over the surface interfering with the metal dissolution. The cathodic branch showed a limiting current region associated to oxygen diffusion which decreased with increasing temperature, showing the effect of mass transport or concentration polarization. The pitting potential for the three conditions appeared around $-80 \mathrm{mV}$.

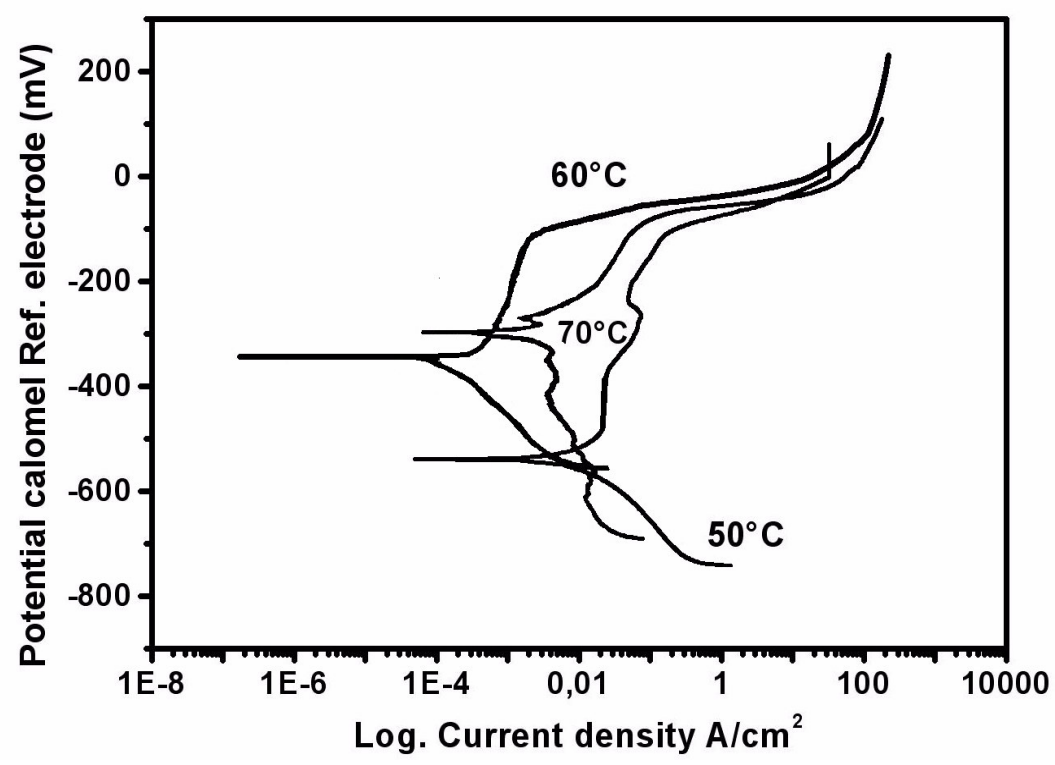

Figure 8. Polarization curves of SS-304 stainless steel exposed to 50 wt. \% $\mathrm{LiBr}-\mathrm{H}_{2} \mathrm{O}$ at the test temperatures.

The Tafel slopes were determined for the three test temperatures, being next: for $50{ }^{\circ} \mathrm{C}$ ba $=66 \mathrm{mV} / \mathrm{dec}$ and $\mathrm{bc}=48 \mathrm{mV} / \mathrm{dec}$; for $60{ }^{\circ} \mathrm{C} \mathrm{ba}=110.6 \mathrm{mV} / \mathrm{dec}$ and $\mathrm{bc}$ $=138 \mathrm{mV} / \mathrm{dec}$; for $70{ }^{\circ} \mathrm{C} \mathrm{ba}=76 \mathrm{mV} / \mathrm{dec}$ and $\mathrm{bc}=66 \mathrm{mV} / \mathrm{dec}$. The Tafel slopes 
were used for the calculation of the current density through the Stern-Geary equation.

\section{Comparison of mass loss}

Fig. 9 shows the experimental mass loss in time obtained from electrochemical noise technique for SS-304 stainless steel exposed to 50 wt. $\% \mathrm{BrLi}_{2} \mathrm{H}_{2} \mathrm{O}$ at 50 , 60 and $70{ }^{\circ} \mathrm{C}$. To determine the mass loss in time, the noise resistance $\mathrm{R}_{\mathrm{n}}$ (evaluated as the ratio of the potential noise standard deviation over the current noise standard deviation) has been calculated. Approximately ninety $R_{n}$ data were obtained for each case during 15 days. The $R_{n}\left(\right.$ ohms. $\left.\mathrm{cm}^{2}\right)$ data were used in the Stern-Geary equation to obtain $I_{\text {corr }}\left(\mathrm{mA} / \mathrm{cm}^{2}\right)$, and through the use of Faraday's Law [11], the mass loss was calculated. The Tafel slopes, which were determined from the polarization curves, were used in the Stern-Geary equation [12-14].

The Stern-Geary equation and Faraday Law are showed in equations 1, 2 and 3.

$$
I_{\text {corr }}=\frac{B}{L p r}
$$

being $\mathrm{B}$ a relationship between the Tafel slopes:

$$
B=\frac{b_{\mathrm{a}} b_{c}}{2.303\left(b_{\mathrm{a}}+b_{c}\right)}
$$

Applying the Faraday Law [15], where the mass loss $M$ is given in $\mathrm{g} / \mathrm{cm}^{2}$ :

$$
\mathrm{M}=\mathrm{K} \mathrm{I}_{\text {corr }}(\mathrm{EW})
$$

$\mathrm{EW}$ is the equivalent weight given by:

$$
E W=\frac{1}{\sum \frac{n_{i} f_{i}}{A W_{i}}}
$$

where $\mathrm{n}_{\mathrm{i}}$ is the number of transferred electrons during the oxidation process for each element $\mathrm{i}$ of the alloy: 2 for $\mathrm{Ni}$, and 3 for $\mathrm{Fe}$ and $\mathrm{Cr}$, according to the atomic absorption analysis, which indicated the presence of the three elements of the 
stainless steel in the next average concentration in $100 \mathrm{~mL}$ of corrosive solution of the three test temperatures: $\mathrm{Fe}=0.45 \mathrm{mg}, \mathrm{Cr}=0.013 \mathrm{mg}$, and $\mathrm{Ni}=0.15 \mathrm{mg} . \mathrm{f}_{\mathrm{i}}$ is the weight fraction of element $i$ and $A W_{i}$ is the molecular weight of element $i$. To calculate the overall mass loss at each day (see Fig. 10), it was necessary to integrate all data records obtained from the beginning to the end for each day.

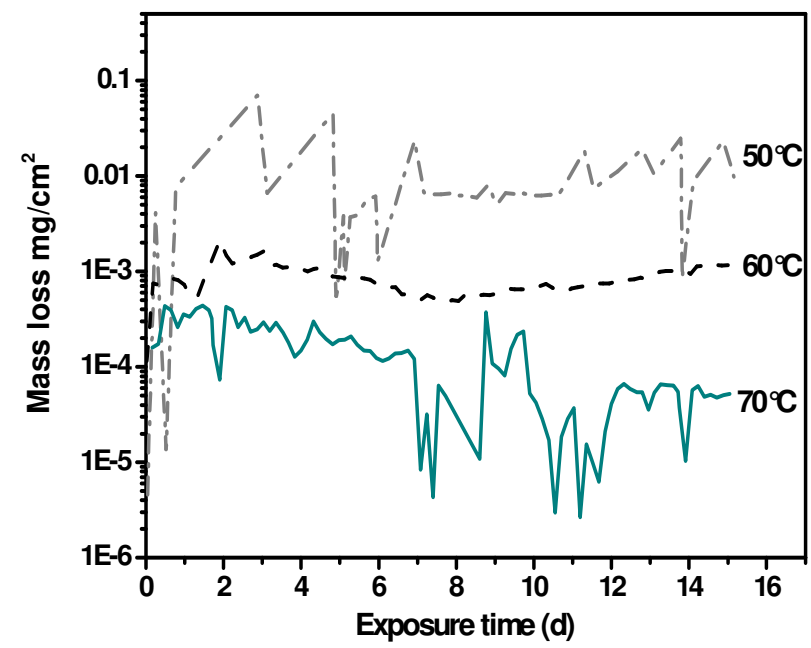

Figure 9. Instantaneous mass loss obtained from electrochemical noise of SS-304 stainless steel exposed to 50 wt. \% $\mathrm{LiBr}-\mathrm{H}_{2} \mathrm{O}$.

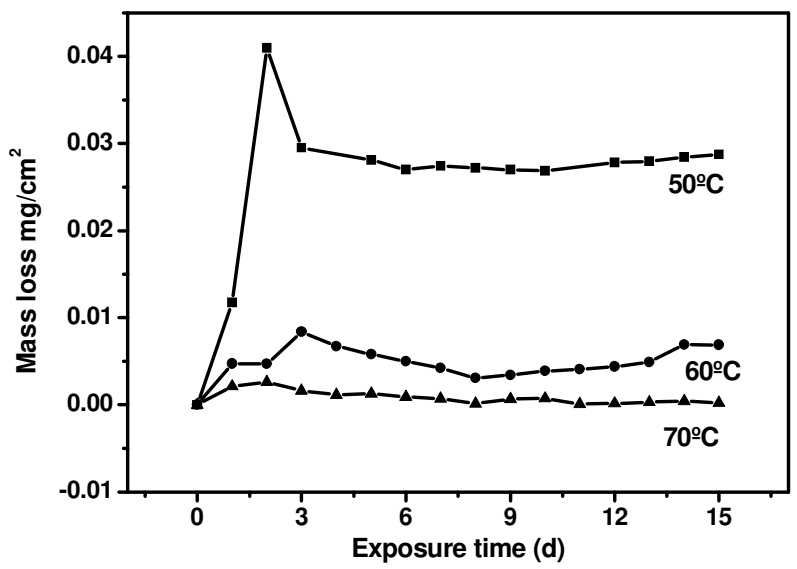

Figure 10. Daily mass loss obtained from electrochemical noise of SS-304 stainless steel exposed to $50 \mathrm{wt}$. \% $\mathrm{LiBr}-\mathrm{H}_{2} \mathrm{O}$ solution.

The instantaneous mass loss presented in Fig. 9 obtained from electrochemical noise of SS-304 showed that the mass loss was inversely proportional to the temperature. This behavior can be explained accordingly to the polarization 
curves at each temperature, where the corrosion potential changes in the noble direction when the temperature increased, indicating the probable formation of corrosion products over the surface, which interfere with the metal dissolution, and consequently yielding to a decrease in corrosion rate with temperature. By the other hand, the fact that cathodic branch showed a decreasing limiting current region associated to oxygen diffusion with an increase in temperature, also indicates the less participation of oxygen as an electro-active specie at the higher temperatures.

The mass loss calculated from electrochemical measurements has been compared to the measured weight loss for 15 days of exposure (Table 1). The results indicate some differences in values; at $50{ }^{\circ} \mathrm{C}$ the mass loss obtained from ENM is higher than that obtained from the weight loss method, whereas at the other two cases the behaviour is on the contrary. The values at $50{ }^{\circ} \mathrm{C}$ are of the same order of magnitude, and at 60 and $70{ }^{\circ} \mathrm{C}$ the values are one order of magnitude of difference. Maybe these differences were due to an excessive cleaning made to the weight loss specimens after immersion and the uncertainty of very low values of mass loss generating in very small specimens.

Table 1. Comparison of mass loss obtained from the electrochemical noise technique and the weight loss method during 15 days for SS-304 exposed to 50 wt. \% $\mathrm{BrLi}-\mathrm{H}_{2} \mathrm{O}$.

\begin{tabular}{ccc}
\hline Temperature $/{ }^{\circ} \mathrm{C}$ & $\begin{array}{c}\text { Electrochemical noise technique } \\
/\left(\mathrm{mg} / \mathrm{cm}^{2}\right)\end{array}$ & $\begin{array}{c}\text { Weight loss method } / \\
\left(\mathrm{mg} / \mathrm{cm}^{2}\right)\end{array}$ \\
\hline 50 & 0.44 & 0.26 \\
60 & 0.08 & 0.6 \\
70 & 0.013 & 0.31 \\
\hline
\end{tabular}

\section{Pitting index}

To corroborate the information about the corrosion process obtained by the electrochemical noise method, the pitting index PI as an indicator of localized corrosion activity (ratio between the current noise standard deviation $\sigma_{i}$ over the root-mean-square current value $\left.\mathrm{I}_{\mathrm{rms}}\right)[3,16]$ has been calculated. The analysis took into account the different ranges of the pitting index: for general corrosion or passive conditions, PI values lie between 0.001-0.01; for mixed corrosion 
between 0.01-0.1; and for localized corrosion between 0.1-1.0 [3]. The values of the pitting index are shown in Fig. 11 . At $50{ }^{\circ} \mathrm{C}$ the pitting index values were the highest respect to the values of the highest temperatures. In general, at the three temperatures the corrosion process was mixed and pitting behavior. The results of pitting index are in agreement with the signals of current time series; hence, the pitting index may supplement what current noise signals are capable to show through noise-time series records.

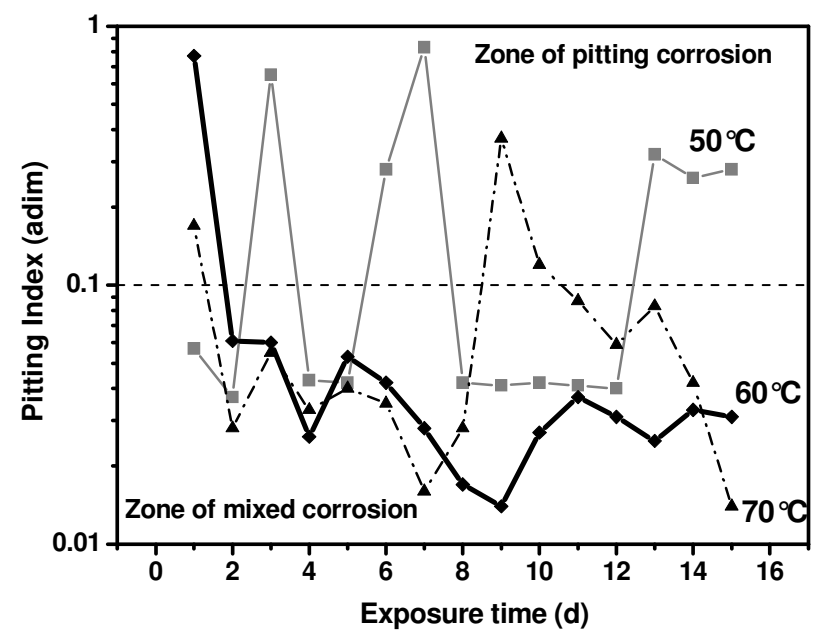

Figure 11. Pitting index of corrosion process of SS-304 stainless steel exposed to $50 \mathrm{wt}$. $\% \mathrm{LiBr}-\mathrm{H}_{2} \mathrm{O}$ solution at different temperatures.

\section{Conclusions}

According to the experimental results obtained for SS-304 stainless steel exposed to a lithium bromide aqueous solution at different temperatures, it is concluded: 1 - the process appears to be controlled by oxygen diffusion;

2- here is a decreasing effect of temperature on the corrosion rate of the metal;

3 - corrosion proceeds under localized or mixed conditions;

4- according to atomic absorption analysis, it is possible the formation of three oxide films on the metal, maybe $\mathrm{F}_{2} \mathrm{O}_{3}, \mathrm{NiO}$, and $\mathrm{Cr}_{2} \mathrm{O}_{3}$, which are the most stable oxides of iron, chromium and nickel. 


\section{References}

1. ASTM Standard G1: Practice for Preparing, Cleaning, and Evaluating Corrosion Test Specimens, (1994).

2. ASTM Standard G31: Practice for Laboratory Immersion Corrosion Testing of Metals, (1995).

3. D.M. Farrell, W.M. Cox, F.H. Stott, D.A. Eden, J.L. Dawson and G.C. Wood, High Temperature Technology, pp.15-21, (1985).

4. Robert G. Kelly, "Corrosion Test and Standards Manual, Application and Interpretation" Chapter 18: Pitting. R. Baboian (ed), ASTM, Manual Series: MNL20, pp. 166-173, (1995).

5. R. Cottis and S. Turgoose, "Corrosion Testing Made Easy: Electrochemical Impedance and Noise", Barry C. Syrett (Series Editor), NACE International, (1999).

6. R.C. Vazquez, G. Rios, A. Trejo, R.E. Rincon, J. Uruchurtu and J.M. Malo, CORROSION/2000, (NACE-International), paper 696, pp. 696/1-696/11, (2000).

7. M.A. Hernández, F.J. Rodríguez, J. Genescá, E. García, F.J. Boerio, CORROSION/99, (NACE-International), paper 197, pp. 197/1-197/13, (1999).

8. C.B. Breslin, A.L. Rudd, Corrosion Science 42 (2000) 1023-1039.

9. J. Goellner, A. Burkert, A. Heyn, J. Hickling, H.U. Vogler, CORROSION/2000, (NACE-Intenational), paper 430, pp. 430/1-430/14, (2000).

10. Y.F. Cheng, M. Wilmott, J.L Luo, "Analysis of the role of electrode on the initiation of pits for A516 carbon steel by electrochemical noise measurements", Corrosion Science 41 (1999) 1245-1256.

11. John R. Scully, Robert Baboian (ed.), ASTM Manual Series: MNL 20, chap.7, (1995) 75.

12. A.A. Alawadhi, R.A. Cottis, CORROSION/1999, (NACE-International), paper 207, pp. 207/1-207/24, (1999). 
13. X.Y. Zhou, S.N. Lvov, X.J. Wei, L.G. Benning, D.D. Macdonald, Corrosion Science 44 (2002) 841-860.

14. F. Mansfeld, C.C. Lee and G. Zhang, Electrochimica Acta 43 (3-4) (1998) 435-438.

15. ASTM Standard G102: Practice for calculation of corrosion rates and related information from electrochemical measurements, (1994).

16. A.N. Rothwell, G.L. Edgemon, G.E.C. Bell, CORROSION/1999, (NACEInternational), paper 192, pp. 192/1-192/17, (1999). 